\title{
Combined endoscopic and surgical management of a right intrahepatic bile duct injury during laparoscopic cholecystectomy
}
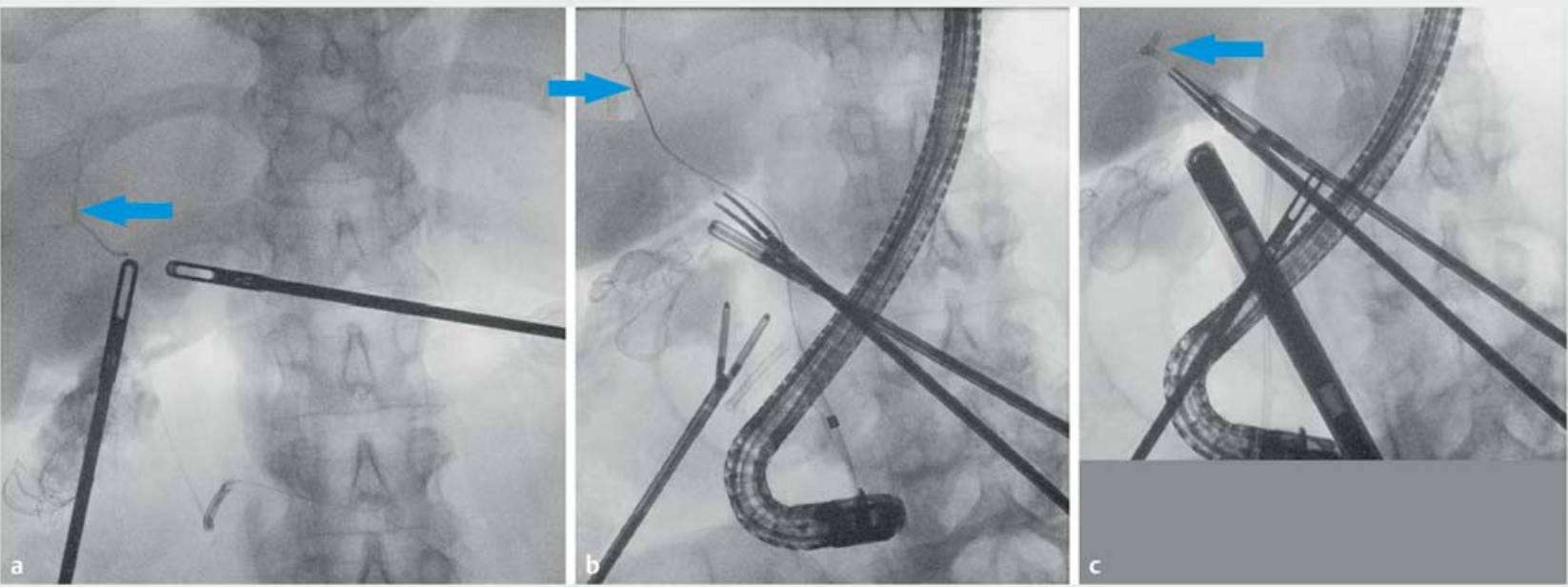

- Fig. 1 Cholangiography during laparoscopic cholecystectomy. a Right posterior intrahepatic bile ducts (arrow). b Right posterior bile duct catheterization with guidewire placement in the right intrahepatic bile duct (arrow). c Placement of a plastic biliary stent (arrow) in the right intrahepatic bile duct to serve as a guide for biliary wound healing.

Biliary tract wounds are a rare complication of cholecystectomy [1]. They lead to the appearance of intra- or extrahepatic biliary stenosis, which usually requires endoscopic treatment [2-4]. They occur mainly when inflammation persists after cholecystitis or angiocholitis. The direct connection of the right posterior bile duct to the common hepatic duct is a well-known anatomical variant of the biliary tract, which can lead to the sectioning of the right posterior bile duct during cholecystectomy [1]. We report here the case of a 70-year-old woman who underwent laparoscopic cholecystectomy following acute cholecystitis. During the procedure, bile flow was found after sectioning of the cystic duct. Intraoperative opacification of the biliary tract showed it being in fact the right posterior bile duct. At the same time, an endoscopic retrograde cholangiopancreatography (ERCP) with endoscopic sphincterotomy was performed. After biliary wound catheterization, the guidewire was introduced inside the right posterior bile ducts laparoscopically ( Fig. 1). A $7 \mathrm{Fr} \times 15 \mathrm{~cm}$
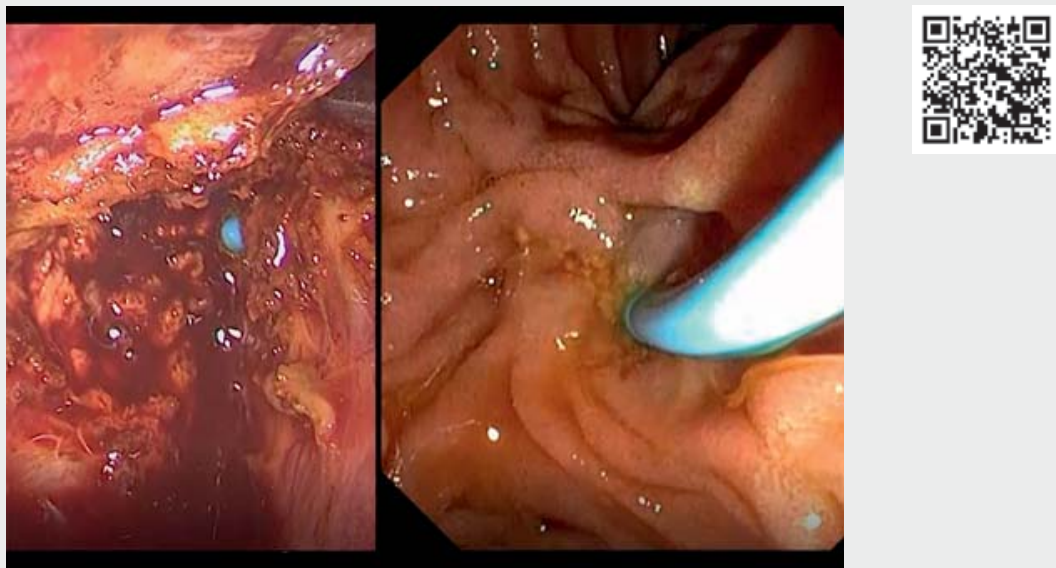

Video 1 Endoscopic retrograde cholangiopancreatography during laparoscopic cholecystectomy with positioning of a biliary plastic stent with laparoscopic guidance for a right posterior bile duct injury.

plastic biliary stent was then placed under endoscopic, fluoroscopic, and laparoscopic guidance inside the right posterior bile ducts to aid healing of the bile duct ( video 1).
Magnetic resonance imaging of the biliary tract was performed 2 months later ( Fig.2). It did not reveal any anomaly of the bile ducts and the stent was still in place. A new ERCP was performed to 


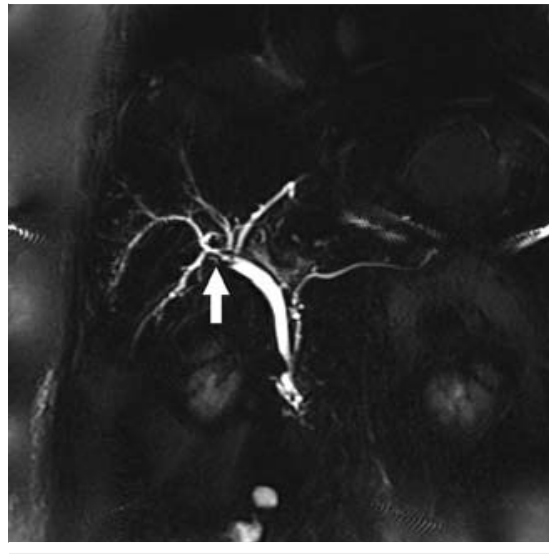

- Fig. 2 Biliary magnetic resonance imaging 2 months after the plastic stent was placed, showing healing of the right posterior hepatic duct (arrow).

remove the stent. Retrograde cholangiography found no biliary leakage but instead satisfactory opacification of the entire biliary tree ( $\triangleright$ Fig. 3 ).

This case illustrates the effectiveness of immediate and joint management of biliary leakage during cholecystectomy. The immediate stent placement aided healing but also ensured patency of the injured bile duct and thus avoided the occurrence of biliary stenosis [5].

Endoscopy_UCTN_Code_TTT_1AR_2AG

\section{Acknowledgement}

This work was supported by French state funds managed within the "Plan Investissements d'Avenir" and by the ANR (reference ANR10-IAHU-02).

\section{Competing interests}

The authors declare that they have no conflict of interest.

The authors

\footnotetext{
Pierre Mayer ${ }^{1,2} \odot$, Lucile Héroin ${ }^{1,2} \odot$, François

Habersetzer ${ }^{1,3}$, Michel Vix ${ }^{2,4}$, Patrick

Pessaux ${ }^{2,4}$, Emanuele Felli ${ }^{2,4}$, Guillaume

Mathis ${ }^{2,4}$

1 Department of Hepatology and

Gastroenterology, Pôle Hépato-digestif,

Nouvel Hôpital Civil, Hôpitaux Universitaires de Strasbourg (HUS), Strasbourg, France
}
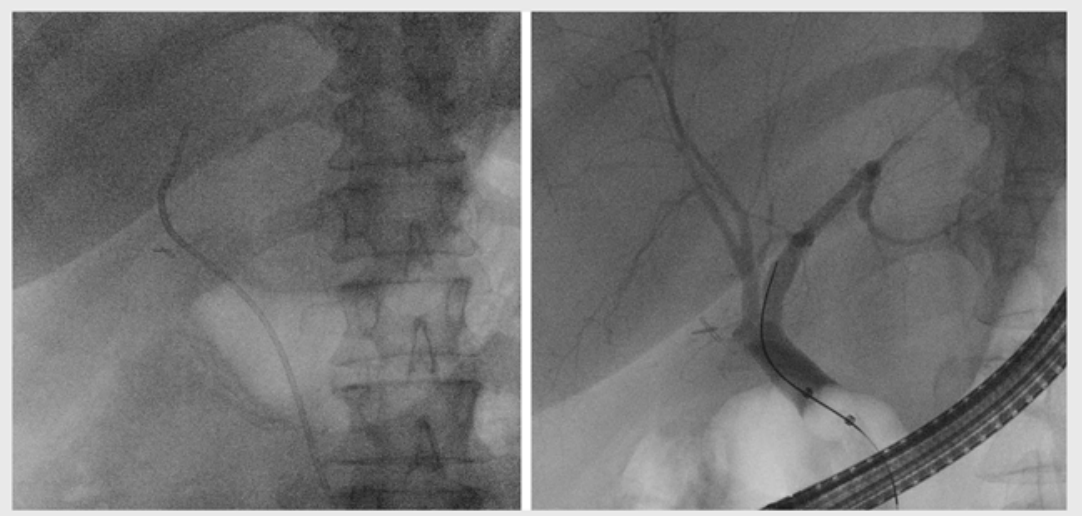

- Fig. 3 Endoscopic retrograde cholangiopancreatography performed 2 months after laparoscopic cholecystectomy with biliary stent ablation and cholangiography.

2 IHU-Strasbourg (Institut HospitaloUniversitaire), Strasbourg, France

3 Inserm U1110, Institute for Viral and Liver Diseases, LabEx HepSYS, University of Strasbourg, Faculty of Medicine, Strasbourg, France

4 Department of Visceral and Digestive Surgery Pôle Hépato-digestif, Nouvel Hôpital Civil, Hôpitaux Universitaires de Strasbourg (HUS), Strasbourg, France

\section{Corresponding author}

\section{Pierre Mayer, MD}

Department of Hepatology and

Gastroenterology, Pôle Hépato-digestif, Nouvel Hôpital Civil, Hôpitaux Universitaires de Strasbourg (HUS), 1, place de l'hôpital, 67000 Strasbourg, France

pierre-emmanuel.mayer@chru-strasbourg.fr

\section{References}

[1] Strasberg SM. Avoidance of biliary injury during laparoscopic cholecystectomy. J Hepatobiliary Pancreat Surg 2002; 9: 543-547

[2] Chow S, Bosco JJ, Heiss FW et al. Successful treatment of post-cholecystectomy bile leaks using nasobiliary tube drainage and sphincterotomy. Am J Gastroenterol 1997; 92: 1839-1843

[3] Rainio M, Lindström O, Udd M et al. Endoscopic therapy of biliary injury after cholecystectomy. Dig Dis Sci 2018; 63: 474-480

[4] Schmitt CM, Baillie J, Cotton PB. ERCP following laparoscopic cholecystectomy: a safe and effective way to manage CBD stones and complications. HPB Surg 1995; 8: 187 192
[5] Pesce A, Palmucci S, La Greca G et al. latrogenic bile duct injury: impact and management challenges. Clin Exp Gastroenterol 2019; $12: 121-128$

\section{Bibliography}

Endoscopy 2022; 54: E682-E683

DOI 10.1055/a-1743-1878

ISSN 0013-726X

published online 18.2.2022

(c) 2022. Thieme. All rights reserved.

Georg Thieme Verlag KG, Rüdigerstraße 14, 70469 Stuttgart, Germany

\section{ENDOSCOPY E-VIDEOS}

https:/|eref.thieme.de/e-videos

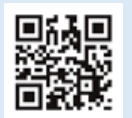

Endoscopy E-Videos is an open access online section, reporting on interesting cases and new techniques in gastroenterological endoscopy. All papers include a high quality video and all contributions are freely accessible online. Processing charges apply (currently EUR 375), discounts and wavers acc. to HINARI are available.

This section has its own submission website at https://mc.manuscriptcentral.com/e-videos 